archives-ouvertes

\title{
Improved NMR Detection of Phospho-Metabolites in a Complex Mixture
}

\author{
Neil Cox, Pierre Millard, Cyril Charlier, Guy Lippens
}

\section{To cite this version:}

Neil Cox, Pierre Millard, Cyril Charlier, Guy Lippens. Improved NMR Detection of PhosphoMetabolites in a Complex Mixture. Analytical Chemistry, American Chemical Society, In press, 93 (11), pp.4818-4824. 10.1021/acs.analchem.0c04056 . hal-03171690v2

\section{HAL Id: hal-03171690 https: / hal.archives-ouvertes.fr/hal-03171690v2}

Submitted on 28 Sep 2021

HAL is a multi-disciplinary open access archive for the deposit and dissemination of scientific research documents, whether they are published or not. The documents may come from teaching and research institutions in France or abroad, or from public or private research centers.
L'archive ouverte pluridisciplinaire HAL, est destinée au dépôt et à la diffusion de documents scientifiques de niveau recherche, publiés ou non, émanant des établissements d'enseignement et de recherche français ou étrangers, des laboratoires publics ou privés. 


\title{
Improved NMR Detection of Phospho-Metabolites in a Complex Mixture
}

\author{
Neil Cox, Pierre Millard, Cyril Charlier, and Guy Lippens*
}

ABSTRACT: Phosphorylated metabolites are omnipresent in cells, but their analytical characterization faces several technical hurdles. Here, we detail an improved NMR workflow aimed at assigning the high-resolution subspectrum of the phosphometabolites in a complex mixture. Combining a pure absorption J-resolved spectrum (Pell, A. J.;et al. J. Magn. Reson. 2007, 189 (2), 293-299) with alternate on- and off-switching of the ${ }^{31} \mathrm{P}$ coupling interaction during the $t_{1}$ evolution with a pure in-phase (PIP) HSQMBC experiment (Castañar, L.;et al. Angew. Chem., Int. Ed. 2014, 53 (32), 8379-8382) without or with total correlation spectroscopy (TOCSY) transfer during the insensitive nuclei enhancement by polarization transfer (INEPT) gives access to selective identification of the individual subspectra of the phosphorylated metabolites. Returning to the initial $J$-res spectra, we can extract with optimal resolution the full trace for the individual phospho-metabolites, which can then be transposed on the high-resolution quantitative one dimensional spectrum.

\section{INTRODUCTION}

The metabolome of a living organism is defined as the collective set of small molecules that are produced by cells, and hence provides a direct snapshot of cellular activity and/or physiological status. In the era of -omics approaches of biology, mass spectrometry (MS) and nuclear magnetic resonance (NMR) spectroscopy are currently the techniques of choice for their analytical characterization. Both techniques are complementary, with MS benefiting from a superior sensitivity, bringing single-cell metabolomics within range, ${ }^{1-3}$ whereas NMR allows us to study molecules directly in solution and can, for example, resolve isomers from the same molecule. ${ }^{4-6}$ Ideally, the latter technique might also give direct access to the metabolome characterization inside the cells. ${ }^{7,8}$ Over the recent years, this exciting perspective has come closer due to major advances toward improved NMR analyses of cell suspensions, ${ }^{8}$ in particular with the development of ${ }^{13} \mathrm{C}$ hyperpolarization based on the dynamic nuclear polarization (DNP) technique ${ }^{9,10}$ together with fast acquisition methods. $^{11-13}$

Because life has chosen adenosine 5' -triphosphate (ATP) as the general energy currency, the phosphate moiety can be found in a large fraction of biomolecules. ${ }^{14}$ A genome-scale model of the model bacteria Escherichia coli, for example, estimated that $43 \%$ of its metabolome would carry at least one phosphate group. ${ }^{15}$ However, the identification of the phospho-metabolome is rather challenging. Especially for the many phosphorylated carbohydrates that act as intermediates in, for example, the glycolytic ${ }^{16}$ or the pentose phosphate ${ }^{17}$

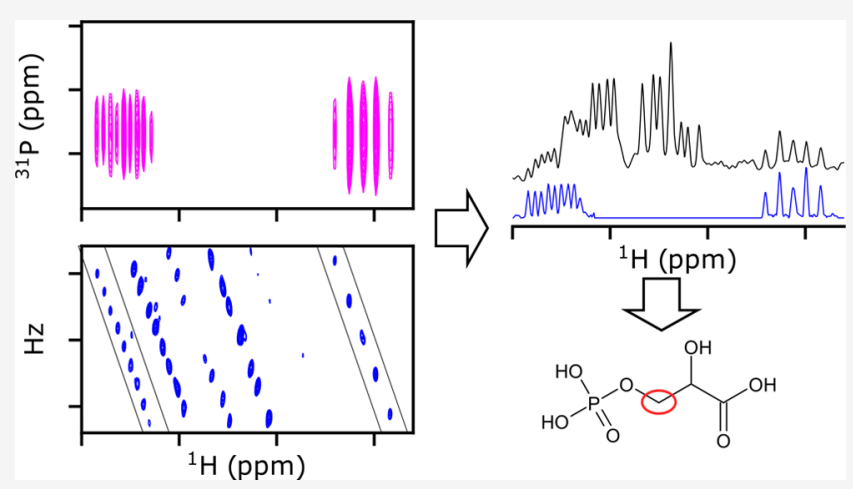

pathways, both mass and NMR spectroscopy face severe technical difficulties. Their hydrophilicity hinders physical separation by reversed-phase liquid chromatography before mass analysis, whereas their analysis as a mixture by tandem mass spectrometry (MS/MS) is plagued by the presence of various structural isomers with similar fragmentation patterns. ${ }^{18}$ For NMR, early studies of the metabolism of different organisms extensively used direct detection of the $100 \%$ abundant spin-1/2 ${ }^{31} \mathrm{P}$ nucleus, ${ }^{7,19-21}$ but its decreased sensitivity compared to proton NMR (due to its lower gyromagnetic ratio and generally larger line widths) and the important influence on the chemical shift of external factors such as $\mathrm{pH}$ and $\mathrm{Mg}^{2+}$ concentration all have contributed to its reduced attractivity in metabolomics studies. But proton NMR equally has its limits. For the glycolytic intermediates of interest here, for example, both the ${ }^{31} \mathrm{P}$ and ${ }^{1} \mathrm{H}$ signals are all clustered in a narrow range of chemical shift values. ${ }^{22}$ As a result, molecular databases contain relatively few phosphometabolites. Only spectra of glucose-6-phosphate (G6P) are present in all major databases, ${ }^{23-27}$ whereas fructose-6phosphate $(\mathrm{F} 6 \mathrm{P})$ or fructose-1,6-phosphate (FBP), the next

Received: September 25, 2020

Accepted: February 18, 2021 
intermediates, only have their spectra recorded in the Biological Magnetic Resonance Bank (BMRB) database. ${ }^{23}$ Finally, the above-mentioned condition-dependent values of the chemical shift hamper database searches on the sole criterion of chemical shift, and alternatives will be clearly needed.

As a result of these combined technical challenges, only very recently attention has shifted to an extensive characterization of this subset of metabolites. Selective immobilization of the phospho-metabolites via metal-ion affinity ${ }^{28}$ or the use of ionexchange chromatography ${ }^{29-31}$ has improved the coverage by mass spectrometry. For NMR, indirect detection schemes have been developed ${ }^{22,32,33}$ that effectively lead to selective detection of only those protons coupled to a phosphorus nucleus. However, these experiments are mostly run with ${ }^{31} \mathrm{P}$ decoupling during acquisition, which not only limits the overall resolution but also modifies the coupling patterns in the slices extracted from the ${ }^{1} \mathrm{H}-{ }^{31} \mathrm{P}$ correlation spectrum. Comparing those slices to the high-resolution proton one-dimensional (1D) NMR spectrum, which remains the standard experiment when multiple samples have to be analyzed, thereby becomes complex. Indeed, the ${ }^{31} \mathrm{P}$ decoupling achieves selective removal of the hetero- but not homonuclear coupling constants, and contrary to the case of ${ }^{13} \mathrm{C}$ spectroscopy, ${ }^{1} \mathrm{H}-{ }^{1} \mathrm{H}$ and ${ }^{1} \mathrm{H}-{ }^{31} \mathrm{P}$ couplings are of the same order of magnitude. Accordingly, in our recent NMR study of the metabolome of the zebra mussel Dreissena polymorpha as a model system for ecotoxicological monitoring, we could only assign a couple of phosphometabolites. $^{34}$

The issue of ${ }^{1} \mathrm{H}-{ }^{1} \mathrm{H}$ couplings as a limiting factor for resolution has in recent years been treated by the resurrection of the J-resolved NMR technique $25,35,36$ together with a boom in pure-shift NMR techniques. ${ }^{37-39}$ However, both techniques address the issue of homonuclear couplings as a problematic effective broadening leading to significant signal overlap in the spectra of complex mixtures. Still, these same patterns carry valuable information that is notoriously condition-independent $^{40}$ and can help in the identification of the metabolites. Ideally, one would like to retain a selective detection of the phospho-metabolites and their intricate coupling patterns as observables in a high-resolution 1D NMR spectrum. Although not (yet) a general practice, providing a high-resolution annotated proton spectrum with the full multiplicity for any given proton has the potential to accelerate further exploitation of the data for future metabolic studies. ${ }^{34,41}$ In the present work, we detail our novel workflow, which brings closer this aim for the subspectrum of the phospho-metabolites (Figure 1). A first entry point is a pure absorption $J$-resolved spectrum $^{42}$ with alternate on- and off-switching of the ${ }^{31} \mathrm{P}$ coupling interaction during the $t_{1}$ evolution. Subtraction of both subspectra leads to the selective observation of the ${ }^{31} \mathrm{P}$ coupled protons while maintaining the complete homo- and heteronuclear coupling patterns. The pure in-phase (PIP) HSQMBC experiment introduced by Castañar and coworkers ${ }^{43}$ can give the same information under the condition that the heteronuclear ${ }^{31} \mathrm{P}$ decoupling is switched off during acquisition, allowing lengthening of the acquisition time and hence resolution enhancement at no cost at all. To identify the additional proton signals of the detected phosphorylated metabolites, we implemented during the insensitive nuclei enhancement by polarization transfers (INEPT) a total correlation spectroscopy (TOCSY)-like transfer from the ${ }^{31} \mathrm{P}$ coupled protons to the other protons of the metabolite. ${ }^{44,45}$

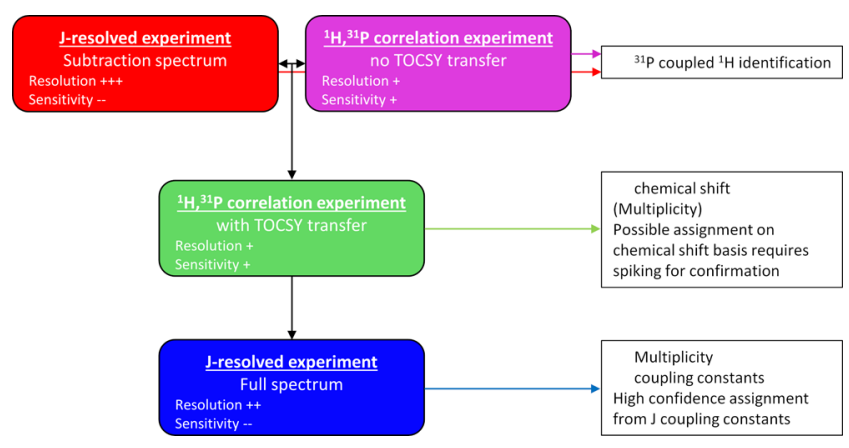

Figure 1. Schematic representation of the NMR workflow to detect phospho-metabolites.

The resulting experiment thereby selectively identifies the whole trace of the metabolite at the given ${ }^{31} \mathrm{P}$ frequency, and proton resolution is maintained by again omitting ${ }^{31} \mathrm{P}$ decoupling during the detection. Finally, returning with this trace to the initial $J$-res spectra, we can extract with optimal resolution the full trace for the individual phospho-metabolites, which then can be transposed on the high-resolution quantitative one dimensional spectrum. We demonstrate the workflow on a simple standard solution containing selected phospho-metabolites to discuss different practical considerations. We then apply it to a complex biological sample that is an active bacterial cell extract, wherein the addition of glucose leads to accumulation of the different phospho-metabolites from the glycolysis pathway. ${ }^{46,47}$

\section{${ }^{31}$ P-SELECTIVE J-RES PULSE SEQUENCE}

In our effort to establish an easy measurement of the ${ }^{13} \mathrm{C}$ flow from labeled precursors into its cellular products, ${ }^{48}$ we developed a pure-shift ${ }^{13} \mathrm{C}$ heteronuclear $J$-resolved pulse sequence that maintains solely ${ }^{1} \mathrm{H}-{ }^{13} \mathrm{C}$ heteronuclear coupling patterns. As an intermediate step, we had adapted the PellKeeler homonuclear two-dimensional (2D) J-resolved sequence ${ }^{42}$ by the addition of ${ }^{13} \mathrm{C} \pi$ pulses during the $t_{1}$ delay, thereby dispersing both ${ }^{1} \mathrm{H}-{ }^{1} \mathrm{H}$ and ${ }^{1} \mathrm{H}-{ }^{13} \mathrm{C}$ couplings along the $45^{\circ}$ diagonal. $^{48}$ This experiment suffers from limited sensitivity, as only that part of the sample which is onresonance with the selective $\pi$ pulse (here implemented as a PSYCHE element ${ }^{37}$ ) contributes to the signal. ${ }^{42}$ Based on signal intensity in the first increment of the $2 \mathrm{D}$ experiment, we found a relative $S / \mathrm{N}$ ratio for the isolated $\mathrm{H} 2$ protons of $\beta$-Dglucose of $7 \%$ compared to the same signals in a $1 \mathrm{D}$ proton spectrum recorded with identical acquisition parameters. This limited sensitivity directly influences the quantitative character of the experiment. In a $1 \mathrm{D}$ proton spectrum, quantitative information can indeed be obtained using a relaxation delay of $\geq 10 \mathrm{~s}$, but this is not compatible with the reduced sensitivity of the J-res experiment. Still, although not realistic on real-world samples in view of the inferior sensitivity, we have run both the $1 \mathrm{D}$ and $J$-resolved spectra with 1 or $10 \mathrm{~s}$ relaxation delay on our mix of standards. As a result, we find exactly the same ratio $I(10 \mathrm{~s}) / I(1 \mathrm{~s})$ for the signals in both spectra (Figure S10). This suggests that a correction factor deduced from a comparison of both $1 \mathrm{D}$ spectra can be extrapolated to the intensity of the signals in the $1 \mathrm{~s} J$-resolved experiment. A second source of error, more unexpected, comes from the bandwidth of the PSYCHE pulse element. In their original study, the Manchester group preconized a $30 \mathrm{~ms}$ PSYCHE pulse composed of the vectorial sum of different CHIRP pulses with a $10 \mathrm{kHz}$ 
sweep bandwidth in the presence of a $1.5 \%$ gradient pulse. While exploring the quantitative character of this experiment, we noted that the (3-trimethylsilyl)-2,2,3,3-tetradeuteriopropionate (TSP) resonance was not fully excited on our $800 \mathrm{MHz}$ experiment. Increasing the sweep bandwidth of the CHIRP pulses to $20 \mathrm{kHz}$ solved this problem (Figure S11). Despite these shortcomings, the superior pure absorption line shapes provide a distinctive advantage to the $J$-res experiment when unraveling signals and coupling patterns in crowded regions.

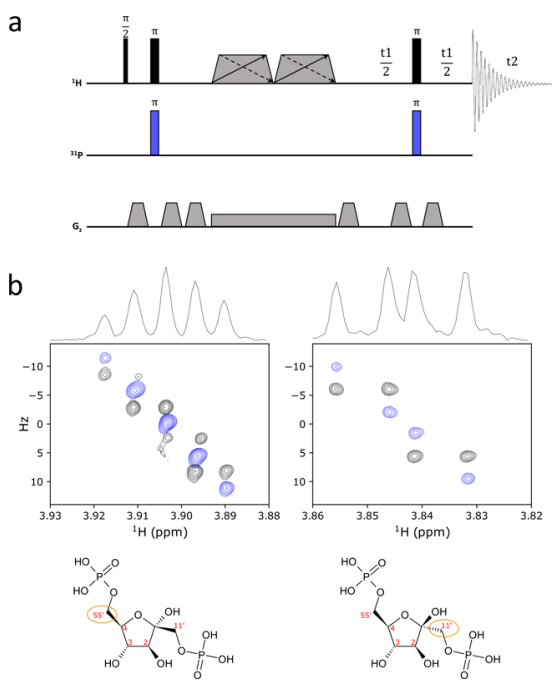

Figure 2. (a) Pulse sequence for the Pell-Keeler ${ }^{1} \mathrm{H},{ }^{31} \mathrm{P} J$-res experiment. The ${ }^{31} \mathrm{P} \pi$ pulses (in blue) are applied in an alternating manner with full or zero power, thereby generating two separate spectra. (b) Superposition of 2D J-res spectra without (black) or with (blue) ${ }^{31} \mathrm{P} \pi$ pulses and hence without or with ${ }^{1} \mathrm{H}-{ }^{31} \mathrm{P}$ coupling evolution during $t_{1}$. The spectrum was acquired on a $5 \mathrm{mM}$ fructose1,6-bisphosphate (FBP) standard in phosphate buffer $\mathrm{pH} 7$.

Applying the $\pi$ pulses on the ${ }^{31} \mathrm{P}$ rather than on the ${ }^{13} \mathrm{C}$ channel (Figures 2 and S1) disperses the heteronuclear ${ }^{1} \mathrm{H}-{ }^{31} \mathrm{P}$ coupling along the same $45^{\circ}$ axis as the homonuclear couplings. However, the comparable value of the ${ }^{1} \mathrm{H}-{ }^{31} \mathrm{P}$ hetero- and ${ }^{1} \mathrm{H}-{ }^{1} \mathrm{H}$ homonuclear coupling constants makes selective detection of the latter less obvious. One way around this is to compare two spectra without and with the ${ }^{31} \mathrm{P} \pi$ pulses. In the first case, the ${ }^{1} \mathrm{H}-{ }^{31} \mathrm{P}$ coupling will be refocused during the $t_{1}$ delay, only appearing during the direct $t_{2}$ detection period. In the second case, it will evolve during both evolution times, thus showing up along the diagonal. Distinguishing the geminal protons for FBP at the C1 or C2 position (Figure 2) thereby becomes straightforward, as the isolated 1 and $1^{\prime}$ protons show up as a homonuclear doublet with an additional ${ }^{31} \mathrm{P}$ coupling. The 5 and $5^{\prime}$ protons additionally couple to the $\mathrm{H} 4$ proton, and the resulting doublet of doublet combines with the additional coupling to the ${ }^{31} \mathrm{P}$ nucleus and leads to an apparent quintuplet (Figure 2).

After subtraction of both spectra, the remaining positive contours represent only the ${ }^{31} \mathrm{P}$-coupled protons and hence act as a selectivity filter for the latter (Figure S2). To improve the robustness of the subtraction, we encoded an interleaved pulse sequence by alternate recording of the $1 \mathrm{D}$ traces for every $t_{1}$ increment without or with the ${ }^{31} \mathrm{P} \pi$ pulses (Figure 1 ). Zeroing the trapezia left and right of a diagonal corresponding to a particular proton before projecting the remaining diagonal as a positive sum generates the ${ }^{1} \mathrm{H}$ spectrum of this ${ }^{31} \mathrm{P}$-coupled proton (Figure 3). Importantly, we do not tilt the spectra at any time, thereby maintaining the excellent line shape of the experiment, which is important in complex mixtures. ${ }^{49}$ Reminiscent to the distant dipolar field (DDF) resolution
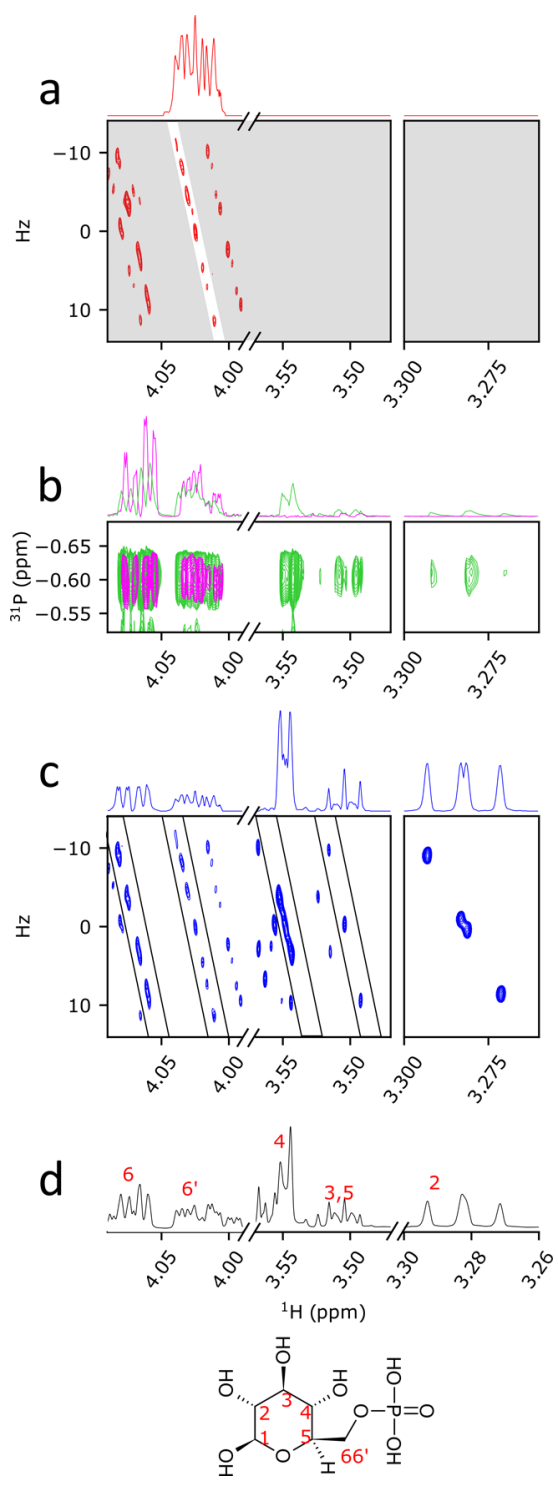

Figure 3. Identification of G6P in a standard mix (10 mM ATP dihydroxyacetone phosphate (DHAP) G6P threonine). (a) J-res difference spectrum (red) selects the signal of proton groups coupled to a ${ }^{31} \mathrm{P}$ nucleus. Extraction of the $45^{\circ}$ strip of the spectrum gives the individual 1D spectrum of the selected proton, shown here as a projection. (b) This signal serves as a starting point for identification of the protons in the $2 \mathrm{D}{ }^{1} \mathrm{H},{ }^{31} \mathrm{P}$ PIP-HSQMBC correlation spectrum without (pink) or with (green) a TOCSY transfer during the INEPT delay and hence full assignment of the phospho-metabolite signals. (c) Returning with this trace to the $J$-res spectrum with ${ }^{31} \mathrm{P} J$-coupling evolution during $t_{1}$ gives access to a high-resolution spectrum with the full coupling patterns and constants, thereby helping the identification of the molecule (here $\beta$-D-glucose-6-phosphate). (d) Finally, this information can be readily transposed to the high-resolution $1 \mathrm{D}$ spectra. Full assignment and coupling constants of the different phospho-metabolites obtained with this workflow are detailed in Figure S5. 
enhanced $J$-res sequence, ${ }^{50}$ we found that the resolution is even better than that of the $1 \mathrm{D}$ spectrum (see, for example, the G6P H3 proton in Figure 3, right panels). However, deducing metabolite concentrations from this $J$-resolved spectrum suffers from various factors, including the short recycling delay and the bandwidth of the PSYCHE pulse (see the Supporting Information (SI)). Without spectral overlap, the same processing can be applied on both the decoupled and nondecoupled spectra, resulting in two identical spectra except for their opposite phase. After phase inversion of one, both can be summed, thereby increasing the signal-to-noise ratio by a factor of $\sqrt{2}$ (Figure S2). To simplify and increase the throughput of this processing, we developed a Python script to be used in Topspin (https://github.com/MetaSys-LISBP/ zerter). Proton signals coupled to a ${ }^{31} \mathrm{P}$ nucleus can thereby be easily extracted, yielding subspectra whereby these particular signals appear as isolated peaks.

\section{COMBINATION WITH ${ }^{1} \mathrm{H},{ }^{31} \mathrm{P}$ CORRELATION EXPERIMENTS}

Heteronuclear ${ }^{1} \mathrm{H},{ }^{31} \mathrm{P}$ correlation experiments have been commonly used for NMR analysis of DNA and/or RNA ${ }^{51,52}$ and were more recently applied to the identification of phospho-metabolites. ${ }^{22,34}$ Because of the importance of resolving homo- and heteronuclear coupling patterns for the protons in the different phospho-metabolites, we applied the pure in-phase (PIP-) HSQMBC sequences previously developed to detect both short- and long-range ${ }^{1} \mathrm{H},{ }^{13} \mathrm{C}$ correlations $^{43}$ without decoupling in the acquisition. This experiment again delivers only the signals of protons directly coupled to a ${ }^{31} \mathrm{P}$ nucleus, but with better sensitivity than the $J$ res experiment. We found that $\mathrm{S} / \mathrm{N}$ for the same glucose signals as described above in the first increment of increases to $27 \%$ of that of the comparable 1D proton spectrum. As signal intensity depends crucially on the coupling interactions, the experiment claims no quantitative character (see the SI). We next implemented a $\pi$ pulse train in an $X Y$-expansion scheme ${ }^{53}$ during the INEPT transfers, thereby obtaining a TOCSY-like transfer from the ${ }^{31} \mathrm{P}$-coupled protons to the other protons of the metabolite (PIP-HSQMBC xy 16, Figure 3). ${ }^{44,45}$ A coupling constant of $6 \mathrm{~Hz}$ was found as the best compromise between the transfer between the ${ }^{31} \mathrm{P}$ nucleus and its coupled protons on one side and the long-range ${ }^{1} \mathrm{H}-{ }^{1} \mathrm{H}$ transfer on the other side (Figure S3). Extracting a row of the latter spectrum at a given ${ }^{31} \mathrm{P}$ chemical shift (orange line Figure $2 \mathrm{a}$ ) shows all proton signals of the corresponding metabolite, but their intensities correspond to the diagonal and cross-peaks in a TOCSY experiment and hence are not representative of the concentrations of the respective protons. However, with these extracted $1 \mathrm{D}$ spectra, we can easily return to the corresponding signals of the $J$-resolved experiment and measure coupling patterns and constants. The trapezia extraction processing proposed above can be used to isolate the spectrum of the whole molecule (Figures 3 and S4) and label the identified molecule in the high-resolution 1D spectrum (Figures 3 and S4). Although we did not detect nucleotides or nucleotide sugars in our cell extract (vide infra), the same workflow remains valid to characterize a mixture of these metabolites as well (Figure S5).

Identification of Phosphorylated Metabolites in a Complex Biological Sample. We next turned to a cell extract of E. coli as a real-world sample. Similarly to what Prof. Buchner found more than a century ago for a yeast extract, ${ }^{46}$ an important number of enzymes remain active in such a cell extract and produce notably the glycolytic intermediates after supplementing the extract with $5 \mathrm{mM}$ glucose. ${ }^{47,54}$ Glycolysis in such a cell extract has been followed in real time by multiple-reaction monitoring with an electrospray ionization (ESI)-MS quadrupole mass spectrometer, ${ }^{47}$ but isomers such as $\mathrm{G} 6 \mathrm{P} / \mathrm{F} 6 \mathrm{P}$ or $2 \mathrm{PG} / 3 \mathrm{PG}$ could not be distinguished. Although the ultimate aim of our NMR setup is to follow the complex reaction network in real time, possibly through simultaneous ${ }^{1} \mathrm{H}$ and ${ }^{31} \mathrm{P}$ detection schemes, ${ }^{55}$ we here aim to assign as far as possible the $1 \mathrm{D}$ proton spectrum in terms of phospho-metabolites. Can we already selectively extract the 1D ${ }^{1} \mathrm{H}$ spectra for these phosphorylated glycolytic metabolites after quenching the extract by a standard ${ }^{56}$ acetonitrile/ methanol protocol? A recent effort to detect those same metabolites by NMR in a synthetic mixture of the purified enzymes concluded that proton NMR leads to too many overlapping signals to allow identification, and the authors therefore returned to ${ }^{31} \mathrm{P}$ NMR with its aforementioned disadvantages. ${ }^{57}$ It is therefore a suitable sample to evaluate the potential for our workflow.

To identify glycolytic metabolites, an aliquot of $E$. coli extract (prepared as described previously; see the SI) was thawed and supplemented with $5 \mathrm{mM}$ glucose (lyophilized). After $20 \mathrm{~min}$, the extract was quenched by addition of $800 \mu \mathrm{L}$ of a cold $(-20$ $\left.{ }^{\circ} \mathrm{C}\right)$ acetonitrile/methanol solution $(1: 1 \mathrm{v} / \mathrm{v})$, vortexed, and kept at $-20{ }^{\circ} \mathrm{C}$ for $1 \mathrm{~h}$ before centrifugation $(15000 \mathrm{~g}, 15 \mathrm{~min}$, $4{ }^{\circ} \mathrm{C}$ ). The supernatant was dried by SpeedVac and stored dry at $-80{ }^{\circ} \mathrm{C}$ until analysis. For NMR analysis, the dried sample was resuspended in $\mathrm{D}_{2} \mathrm{O}$ with $1 \mathrm{mM}$ TSP. Sample $\mathrm{pH}$ was 6.6 (uncorrected $\mathrm{pD}$ measurement). Figure 4 demonstrates the workflow to identify one representative phospho-metabolite (3-phosphoglycerate, 3PG) of the pathway with the J-res difference spectrum as the entry point. The projection of its isolated ${ }^{1} \mathrm{H}$ proton signal in the $J$-res difference spectrum corresponds to a trace from the PIP-HSQMBC spectrum, and extracting the trace at the same ${ }^{31} \mathrm{P}$ frequency in the PIPHSQMBCxy16 spectrum yields the full trace for this metabolite. This trace allows identification of the same signals with an optimal resolution in the original $J$-res spectrum. The signal of the $\mathrm{H}_{2}^{\prime}$ proton at $3.95 \mathrm{ppm}$ thereby unambiguously is a doublet of doublets of doublets. However, when we consider the same signal in the other $J$-res spectrum without the ${ }^{31} \mathrm{P} \pi$ pulses, we immediately see it is a doublet of doublets further split by a ${ }^{1} \mathrm{H}-{ }^{31} \mathrm{P}$ coupling (Figure 4 ). Equally, the line shape of the $\mathrm{H} 2$ proton is slightly different in both sub-J-spectra, which we assign to a small $(0.5 \mathrm{~Hz})$ but nonvanishing coupling constant between this proton and the ${ }^{31} \mathrm{P}$ nucleus (Figure S6). This is confirmed by a weak cross-peak in the PIP-HSQMBC spectrum for this same proton (Figure S6). Interrogating the Human Metabolome Database ${ }^{24}(\mathrm{hmdb})$, the Biomagresbank $^{23}$ (bmrb), or the Birmingham Metabolite Library ${ }^{36}$ (Figure S7), we could assign the three lines to 3PG through matching of the coupling patterns. However, the experimental conditions varying slightly between our extract and the standard conditions used to record the database 3PG entries, chemical shift values are close but not identical (Figure S7), and this will be a recurrent issue for database mining with spectra of phospo-metabolites. Another potentially confounding factor is that the $J$-coupling values when expressed in ppm become field-dependent, ${ }^{58}$ and can thereby distort the apparent pattern. The Birmingham Metabolite library ${ }^{36}$ or SpinCouple $^{25}$ avoids this issue by using tilted spectra and 

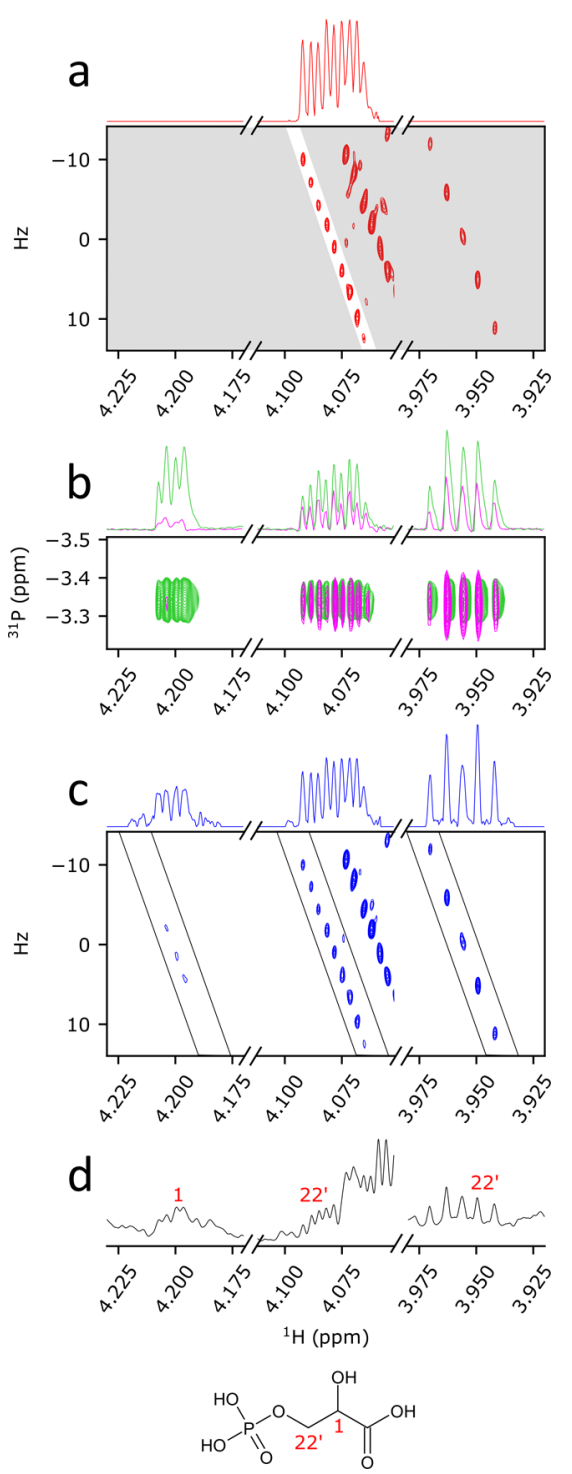

Figure 4. Assignment of 3-phosphoglyceric acid in an E. coli extract. The workflow is identical to that in Figure 3.

assign thereby all lines of a multiplet to a single chemical shift. However, as stated before, this comes at the cost of a deteriorated line shape, ${ }^{49}$ which we avoid due to our projection procedure. The assignment of the different phosphometabolites in the extract is detailed in Figure S8 and gives rise to a fully assigned $1 \mathrm{D}$ spectrum (Figure S9).

FBP is an example where we cannot use the $J$-resolved subtraction spectrum as the entry point, due to limited sensitivity (for a detailed analysis of this parameter, see the Supporting Information) and the presence of its signals in an overly crowded region. However, its signals appear in the PIPHSQMBC spectrum, where they benefit moreover from the spreading due to its particular ${ }^{31} \mathrm{P}$ frequency. Importantly, even though the chemical shift values for FBP between our standard and the cell extract do not coincide perfectly (Figure S8.2), the quadruplet structure of the $\mathrm{C} 1$ linked protons (Figure 2) gives good confidence to the assignment, which we finally verified by spiking of FBP in the cell extract. Taking into account the chemical information available in the literature, such as GA3P being predominantly present in its diol form ${ }^{59}$ or the presence of both a keto- and gem-diol form for DHAP, ${ }^{60}$ we could assign with certainty six of the nine phosphorylated glycolytic intermediates in our spectrum. No distinctive signal suggesting the presence of the three other intermediates (F6P, 2PG, FBP) could be observed in the quenched cell extract. Finally, returning with these assignments to our quantitative onedimensional experiment, we estimated the phospho-metabolite concentrations in this sample as follows: [G6P] $237 \mu \mathrm{M}$; [DHAP] $260 \mu \mathrm{M}$; [3PG]: $789 \mu \mathrm{M}$; [PEP]: $450 \mu \mathrm{M}$.

\section{CONCLUSIONS}

The workflow presented above demonstrates that detailed information on the phospho-metabolome can be extracted from a complex sample using the ${ }^{31} \mathrm{P}$ nucleus as a selectivity filter, overcoming thereby the need to physically separate this particular class of metabolites. Its limitations are obviously related to the low sensitivity of NMR spectroscopy compared to mass spectrometry. However, when we consider that the main aim of the workflow is to provide an accurate annotation of the $1 \mathrm{D}$ spectrum, the extraction of the traces from the $J$ resolved spectrum via the procedure described proved perfectly transposable to the 1D spectrum (Figure 3), thereby clarifying the subspectrum of the phospho-metabolome. Quantitative measurements can be obtained from the annotated 1D proton spectrum, where the issue of differential relaxation times can be solved by a long recycling delay. ${ }^{61}$ Our results on the cellular extract further highlight a number of important points when characterizing the phospho-metabolome. First, chemical shift values alone are not easy to use for an automatic assignment procedure, as they are very sensitive to the exact sample conditions. Second, coupling patterns are more reliable and can be determined with excellent resolution by the here described ${ }^{31} \mathrm{P}$-selective $J$-resolved difference sequence and/or the PIP-HSQMBC sequence without decoupling. Further development of database query algorithms that give access to the precise coupling patterns ${ }^{62}$ would therefore be of great use. Finally, our study shows that NMR spectroscopy remains a valuable complementary technique to mass spectrometry in the effort to characterize the phospho-metabolome.

\section{ASSOCIATED CONTENT}

\section{(3) Supporting Information}

The Supporting Information is available free of charge at https://pubs.acs.org/doi/10.1021/acs.analchem.0c04056.

Details of samples and NMR experiments; analysis of sensitivity and quantitative character; assigned spectra of phospho-metabolites; and additional information as indicated in the text (PDF)

Pulse sequence for the Pell-Keeler ${ }^{1} \mathrm{H},{ }^{31} \mathrm{P} J$-res experiment; different processing modes for the J-res experiment; impact of different $\mathrm{H}-\mathrm{P}$ coupling constants on ${ }^{1} \mathrm{H},{ }^{31} \mathrm{P}$ PIP-HSQMBC $x y 16$ correlation spectra; assignment of available phosphorylated glycolytic intermediates; spectra of a nucleotide standard mix; focus on $\mathrm{H} 1$ signal of 3PG highlighting the effect of small ${ }^{5} \mathrm{~J} \mathrm{H}-\mathrm{P}$ coupling; comparison of spectra of 3phosphoglycerate from different databases; assignment of glucose-6-phosphate, fructose-1,6-bisphosphate, glyceraldehyde 3-phosphate, dihydroxyacetone phosphate and phosphoenolpyruvate in the E. coli cell extract; assigned 1D spectra of the phospho-metabolites in the $E$. coli extract; comparison of $1 \mathrm{D}$ and $J$-res projection acquired with 1 or $10 \mathrm{~s}$ interscan delay; comparison of $J$ - 
res spectra acquired with 10 or $20 \mathrm{kHz}$ PSYCHE pulse; projection from PIP-HSQMBC spectra with and without ${ }^{31} \mathrm{P}$ broadband decoupling (Figures $\mathrm{S} 1-\mathrm{S} 12$ ) (PDF) Assignment of the different phospho-metabolites (XLSX)

\section{AUTHOR INFORMATION}

\section{Corresponding Author}

Guy Lippens - TBI, Université de Toulouse, CNRS, INRAE, INSA, 31077 Toulouse, France; 이이. org/0000-00028236-0901; Phone: +33(0)5-61-55-94-58;

Email: guy.lippens@insa-toulouse.fr

\section{Authors \\ Neil Cox - TBI, Université de Toulouse, CNRS, INRAE, INSA, 31077 Toulouse, France \\ Pierre Millard - TBI, Université de Toulouse, CNRS, INRAE, INSA, 31077 Toulouse, France; 이이.org/0000-0002- 8136-9963 \\ Cyril Charlier - TBI, Université de Toulouse, CNRS, INRAE, INSA, 31077 Toulouse, France}

Complete contact information is available at:

https://pubs.acs.org/10.1021/acs.analchem.0c04056

\section{Notes}

The authors declare no competing financial interest.

\section{ACKNOWLEDGMENTS}

The authors thank Dr. D Sinnaeve (Lille, France) for precious help with the PSYCHE pulse element and Dr. H Kulyk (Métatoul, Toulouse, France) for insightful discussions about mass spectrometry. Dr. E Cahoreau and L. Peyriga provided expert support for the NMR facility. This project has received funding from the European Union's Horizon 2020 research and innovation programme under grant agreement no. 862179 . MetaToul (Toulouse metabolomics \& fluxomics facilities, www.metatoul.fr) is part of the French National Infrastructure for Metabolomics and Fluxomics MetaboHUB-AR-11-INBS0010 (www.metabohub.fr) and is supported by the Région Midi-Pyrénées, the ERDF, the SICOVAL, and the French Minister of Education \& Research, who are all gratefully acknowledged.

\section{REFERENCES}

(1) Zenobi, R. Science 2013, 342, No. 1243259.

(2) Duncan, K. D.; Fyrestam, J.; Lanekoff, I. Analyst 2019, 144, 782-793.

(3) Minakshi, P.; Ghosh, M.; Kumar, R.; Patki, H. S.; Saini, H. M.; Ranjan, K.; Brar, B.; Prasad, G. Single-Cell Metabolomics: Technology and Applications. In Single-Cell Omics; Barh, D.; Azevedo, V., Eds.; Academic Press, 2019; Chapter 15, pp 319-353.

(4) Bingol, K.; Brüschweiler, R. Curr. Opin. Clin. Nutr. Metab. Care 2015, 18, 471-477.

(5) Emwas, A.-H.; Roy, R.; McKay, R. T.; Tenori, L.; Saccenti, E.; Gowda, G. A. N.; Raftery, D.; Alahmari, F.; Jaremko, L.; Jaremko, M.; Wishart, D. S. Metabolites 2019, 9, No. 123.

(6) Wang, C.; He, L.; Li, D.-W.; Bruschweiler-Li, L.; Marshall, A. G.; Brüschweiler, R. J. Proteome Res. 2017, 16, 3774-3786.

(7) Shulman, R. G.; Brown, T. R.; Ugurbil, K.; Ogawa, S.; Cohen, S. M.; den Hollander, J. A. Science 1979, 205, 160-166.

(8) Lippens, G.; Cahoreau, E.; Millard, P.; Charlier, C.; Lopez, J.; Hanoulle, X.; Portais, J. C. Analyst 2018, 143, 620-629.

(9) Meier, S.; Jensen, P. R.; Duus, J. Ø. ChemBioChem 2012, 13, 308-310.
(10) Dzien, P.; Fages, A.; Jona, G.; Brindle, K. M.; Schwaiger, M.; Frydman, L. J. Am. Chem. Soc. 2016, 138, 12278-12286.

(11) Dass, R.; Grudzia̧ż, K.; Ishikawa, T.; Nowakowski, M.; Dębowska, R.; Kazimierczuk, K. Front. Microbiol. 2017, 8, No. 1306.

(12) Hyberts, S. G.; Arthanari, H.; Robson, S. A.; Wagner, G. J. Magn. Reson. 2014, 241, 60-73.

(13) Kazimierczuk, K.; Orekhov, V. Magn. Reson. Chem. 2015, 53, 921-926.

(14) Westheimer, F. H. Science 1987, 235, 1173-1178.

(15) Orth, J. D.; Conrad, T. M.; Na, J.; Lerman, J. A.; Nam, H.; Feist, A. M.; Palsson, B. Ø. Mol. Syst. Biol. 2011, 7, 535.

(16) Barnett, J. A. Yeast 2003, 20, 509-543.

(17) Stincone, A.; Prigione, A.; Cramer, T.; Wamelmorrisink, M. M. C.; Campbell, K.; Cheung, E.; Olin-Sandoval, V.; Grüning, N.-M.; Krüger, A.; Tauqeer Alam, M.; Keller, M. A.; Breitenbach, M.; Brindle, K. M.; Rabinowitz, J. D.; Ralser, M. Biol. Rev. Cambridge Philos. Soc. 2014, 927.

(18) Hinterwirth, H.; Lämmerhofer, M.; Preinerstorfer, B.; Gargano, A.; Reischl, R.; Bicker, W.; Trapp, O.; Brecker, L.; Lindner, W. J. Sep. Sci. 2010, 33, 3273-3282.

(19) Navon, G.; Ogawa, S.; Shulman, R. G.; Yamane, T. Proc. Natl. Acad. Sci. U.S.A. 1977, 74, 888-891.

(20) Ugurbil, K.; Rottenberg, H.; Glynn, P.; Shulman, R. G. Proc. Natl. Acad. Sci. U.S.A. 1978, 75, 2244-2248.

(21) Cohen, S. M.; Ogawa, S.; Rottenberg, H.; Glynn, P.; Yamane, T.; Brown, T. R.; Shulman, R. G.; Williamson, J. R. Nature 1978, 273, $554-556$.

(22) Bhinderwala, F.; Evans, P.; Jones, K.; Laws, B. R.; Smith, T.; Morton, M. D.; Powers, R. Anal. Chem. 2020, 9536.

(23) Ulrich, E. L.; Akutsu, H.; Doreleijers, J. F.; Harano, Y.; Ioannidis, Y. E.; Lin, J.; Livny, M.; Mading, S.; Maziuk, D.; Miller, Z.; Nakatani, E.; Schulte, C. F.; Tolmie, D. E.; Kent Wenger, R.; Yao, H.; Markley, J. L. Nucleic Acids Res. 2007, 36, D402-D408.

(24) Wishart, D. S.; Tzur, D.; Knox, C.; Eisner, R.; Guo, A. C.; Young, N.; Cheng, D.; Jewell, K.; Arndt, D.; Sawhney, S.; Fung, C.; Nikolai, L.; Lewis, M.; Coutouly, M.-A.; Forsythe, I.; Tang, P.; Shrivastava, S.; Jeroncic, K.; Stothard, P.; Amegbey, G.; Block, D.; Hau, D. D.; Wagner, J.; Miniaci, J.; Clements, M.; Gebremedhin, M.; Guo, N.; Zhang, Y.; Duggan, G. E.; Macinnis, G. D.; Weljie, A. M.; Dowlatabadi, R.; Bamforth, F.; Clive, D.; Greiner, R.; Li, L.; Marrie, T.; Sykes, B. D.; Vogel, H. J.; Querengesser, L. Nucleic Acids Res. 2007, 35, D521-526.

(25) Kikuchi, J.; Tsuboi, Y.; Komatsu, K.; Gomi, M.; Chikayama, E.; Date, Y. Anal. Chem. 2016, 88, 659-665.

(26) Kanehisa, M.; Goto, S. Nucleic Acids Res. 2000, 28, 27-30.

(27) Ellinger, J. J.; Chylla, R. A.; Ulrich, E. L.; Markley, J. L. Curr. Metabolomics 2013, 1, 28-40.

(28) Salim, M.; Fowler, G. J. S.; Wright, P. C.; Vaidyanathan, S. Anal. Chim. Acta 2012, 724, 119-126.

(29) Ritter, J.; Genzel, Y.; Reichl, U. J. Chromatogr. B 2006, 843, 216-226.

(30) Kvitvang, H. F. N.; Bruheim, P. J. Chromatogr. B 2015, 998999, 45-49.

(31) Schwaiger, M.; Rampler, E.; Hermann, G.; Miklos, W.; Berger, W.; Koellensperger, G. Anal. Chem. 2017, 89, 7667-7674.

(32) Gradwell, M. J.; Fan, T. W.; Lane, A. N. Anal. Biochem. 1998, 263, 139-149.

(33) Pollesello, P.; Eriksson, O.; Vittur, F.; Paoletti, S.; Geimonen, E.; Toffanin, R. NMR Biomed. 1995, 8, 190-196.

(34) Prud'homme, S. M.; Hani, Y. M. I.; Cox, N.; Lippens, G.; Nuzillard, J.-M.; Geffard, A. Metabolites 2020, 10, No. 256.

(35) Ludwig, C.; Viant, M. R. Phytochem. Anal. 2010, 21, 22-32.

(36) Ludwig, C.; Easton, J. M.; Lodi, A.; Tiziani, S.; Manzoor, S. E.; Southam, A. D.; Byrne, J. J.; Bishop, L. M.; He, S.; Arvanitis, T. N.; Günther, U. L.; Viant, M. R. Metabolomics 2012, 8, 8-18.

(37) Foroozandeh, M.; Adams, R. W.; Meharry, N. J.; Jeannerat, D.; Nilsson, M.; Morris, G. A. Angew. Chem., Int. Ed. 2014, 53, 69906992. 
(38) Aguilar, J. A.; Cassani, J.; Delbianco, M.; Adams, R. W.; Nilsson, M.; Morris, G. A. Chem. - Eur. J. 2015, 21, 6623-6630.

(39) Castañar, L.; Parella, T. Magn. Reson. Chem. 2015, 53, 399426.

(40) Hierso, J.-C. Chem. Rev. 2014, 114, 4838-4867.

(41) McAlpine, J. B.; Chen, S.-N.; Kutateladze, A.; MacMillan, J. B.; Appendino, G.; Barison, A.; Beniddir, M. A.; Biavatti, M. W.; Bluml, S.; Boufridi, A.; Butler, M. S.; Capon, R. J.; Choi, Y. H.; Coppage, D.; Crews, P.; Crimmins, M. T.; Csete, M.; Dewapriya, P.; Egan, J. M.; Garson, M. J.; Genta-Jouve, G.; Gerwick, W. H.; Gross, H.; Kay Harper, M.; Hermanto, P.; Hook, J. M.; Hunter, L.; Jeannerat, D.; Ji, N.-Y.; Johnson, T. A.; Kingston, D. G. I.; Koshino, H.; Lee, H.-W.; Lewin, G.; Li, J.; Linington, R. G.; Liu, M.; McPhail, K. L.; Molinski, T. F.; Moore, B. S.; Nam, J.-W.; Neupane, R. P.; Niemitz, M.; Nuzillard, J.-M.; Oberlies, N. H.; Ocampos, F. M. M.; Pan, G.; Quinn, R. J.; Sai Reddy, D.; Renault, J.-H.; Rivera-Chávez, J.; Robien, W.; Saunders, C. M.; Schmidt, T. J.; Seger, C.; Shen, B.; Steinbeck, C.; Stuppner, H.; Sturm, S.; Taglialatela-Scafati, O.; Tantillo, D. J.; Verpoorte, R.; Wang, B.-G.; Williams, C. M.; Williams, P. G.; Wist, J.; Yue, J.-M.; Zhang, C.; Xu, Z.; Simmler, C.; Lankin, D. C.; Bisson, J.; Pauli, G. F. Nat. Prod. Rep. 2019, 36, 35-107.

(42) Pell, A. J.; Keeler, J. J. Magn. Reson. 2007, 189, 293-299.

(43) Castañar, L.; Saurí, J.; Williamson, R. T.; Virgili, A.; Parella, T. Angew. Chem., Int. Ed. 2014, 53, 8379-8382.

(44) Kramer, F.; Peti, W.; Griesinger, C.; Glaser, S. J. J. Magn. Reson. 2001, 149, 58-66.

(45) Luy, B.; Marino, J. P. J. Am. Chem. Soc. 2001, 123, 1130611307.

(46) Buchner, E. Ber. Dtsch. Chem. Ges. 1897, 30, 1110-1113.

(47) Bujara, M.; Schümperli, M.; Pellaux, R.; Heinemann, M.; Panke, S. Nat. Chem. Biol. 2011, 7, 271-277.

(48) Sinnaeve, D.; Dinclaux, M.; Cahoreau, E.; Millard, P.; Portais, J.-C.; Létisse, F.; Lippens, G. Anal. Chem. 2018, 90, 4025-4031.

(49) Charris-Molina, A.; Riquelme, G.; Burdisso, P.; Hoijemberg, P. A. J. Proteome Res. 2019, 18, 2241-2253.

(50) Huang, Y.; Zhang, Z.; Chen, H.; Feng, J.; Cai, S.; Chen, Z. Sci. Rep. 2015, 5, No. 8390.

(51) Gorenstein, D. G. Chem. Rev. 1994, 94, 1315-1338.

(52) Ronconi, L.; Sadler, P. J. Coord. Chem. Rev. 2008, 252, 22392277.

(53) Gullion, T.; Baker, D. B.; Conradi, M. S. J. Magn. Reson. (1969)

1990, 89, 479-484.

(54) Laohakunakorn, N.; Grasemann, L.; Lavickova, B.; Michielin, G.; Shahein, A.; Swank, Z.; Maerkl, S. J. Front. Bioeng. Biotechnol. 2020, 8, No. 213.

(55) Cox, N.; Kuemmerle, R.; Millard, P.; Cahoreau, E.; François, J.M.; Parrou, J.-L.; Lippens, G. Anal. Chem. 2019, 3959.

(56) Bennett, B. D.; Kimball, E. H.; Gao, M.; Osterhout, R.; Van Dien, S. J.; Rabinowitz, J. D. Nat. Chem. Biol. 2009, 5, 593-599.

(57) Stevenson, B. J.; Liu, J.-W.; Kuchel, P. W.; Ollis, D. L. J. Biotechnol. 2012, 157, 113-123.

(58) Dinclaux, M.; Cahoreau, E.; Millard, P.; Létisse, F.; Lippens, G. Magn. Reson. Chem. 2020, 305.

(59) Trentham, D. R.; McMurray, C. H.; Pogson, C. I. Biochem. J.

1969, 114, 19-24.

(60) Ślepokura, K.; Lis, T. Carbohydr. Res. 2010, 345, 512-529.

(61) Millard, P.; Cahoreau, E.; Heuillet, M.; Portais, J.-C.; Lippens, G. Anal. Chem. 2017, 89, 2101-2106.

(62) Heinecke, A.; Ye, L.; Iorio, M. D.; Ebbels, T. Bayesian Anal. 2020, 1-34. 